\title{
PHYTOCHEMICAL ANALYSIS, ANTIMICROBIAL AND ANTIOXIDANT ACTIVITIES OF THYMUS VULGARIS L.
}

\author{
Moaiza Iftikhar \\ University of Central Punjab, Lahore, Pakistan \\ Salma Batool* \\ University of Central Punjab, Lahore, Pakistan \\ Salma.batool@ucp.edu.pk
}

\begin{abstract}
:
Medicinal activities of Thymus vulgaris L. were studied in the underlying research which was conducted in University of Central Punjab, Lahore. The powdered plant sample was collected and subjected to extraction and filtration by dissolving it in seven different solvents and thus the fractions obtained, were used for further analysis. The qualitative and quantitative analysis was carried out which revealed that this plant contained many biologically active compounds like saponin, alkaloids etc. These compounds have enormous bioactive roles. Antimicrobial activity was also determined in which four bacterial strains were used and the susceptibility of all the fractions of plant extract was determined by their inhibition zones which were calculated in mm. The results showed that water and chloroform extracts of plant has highest activity. The antioxidant activity was also determined by DPPH scavenging assay for which different concentrations of all plant extracts were made and their absorbance was noted to measure the percentage inhibition of each concentration, which revealed that this plant has significant antioxidant activity. The results have been represented using statistical approach that revealed that $T$. vulgaris plant has significant antibacterial and anti-oxidant activities and phytochemical analysis also proved that it has many useful compounds which have voluminous biological activity and these could be used in the formation of novel drugs.
\end{abstract}

\section{Keywords:}

Phytochemical analysis, antimicrobial assay, antioxidant activity, Thymus vulgaris $l$.

\section{Introduction}

Many plants constitute drug like properties because of which they have been identified as potential drug candidates and are known as medicinal plants worldwide (Bernhoft et al. 2010). They play significant role in maintaining human health globally. These plants have vital history in pharmacology as the usage of plants for medicinal purpose started in ancient times. The different writings and reviews revealed that plants have been used since 4000 - 5000 B.C. for their remedial properties and the people of China were on the top who used these herbs as medicines. Moreover, oldest reference of using plants as medicines appear in Rig-Veda, that was written in 1600 3500 B.C. Years after the medicinal plants were studied in detail for their curative properties and restorative uses, and these details were specifically and carefully recorded by the physicians of that era (originating a system of medicine) which was a base of early medicinal sciences in Indian subcontinent (Prakash \& Gupta, 2005).

The use of medicinal plants is ancient as these were used for restoring health of the living and also to bestowed the meals with spice and flavoring. The dry powder samples and crude extracts of medicinal and aromatic plants and their species have been used for the formulation of new traditional medicines or food supplements (Baydar et al., 2004; Rota et al., 2008). The manufacturing of food additives, formed by oils and extracts of plants with antioxidant and antimicrobial characteristics is deem necessary towards the production of healthy food products, as healthful diet 
is a part of one's lifestyle that nurtures or prolong the safe and sound health conditions. Many spices and herbal extracts are used for preservation of the food, also some of them are used as appetite stimulants and many of them has been used medicinally in old times (Mousavi, Wilson, Raftos, Mirzargar, \& Omidbaigi, 2011). According to WHO, the most useful source for obtaining a huge variety of new drugs is medicinal plants. Traditional medicines that are used by $80 \%$ of the population worldwide, contained such compounds which were derived from herbal plant extracts (Arunkumar \& Muthuselvam, 2009). Medicinal herbs or plants are a rich source and natural mean of medicinal products used traditionally as medicine and chemical constituents for novel drugs.

Biologically active compounds in herbal extracts and spices gained considerable attention during an effort which was made to unfold their immense involvement in maintaining health and also to preserve of food and retaining its quality. The knowledge from recent studies has also indicated that naturally producing polyphenols could be substituted to the use of synthetically produced antioxidants (Babovic et al., 2010; Sulniūte, Pukalskas, \& Venskutonis, 2017). The historical and scientific data revealed that a diet enriched with polyphenols, such as flavonoids and hydroxycinnamic acids, has adequate health properties (Chan, Gan, \& Corke, 2016; Pan, Lai, \& Ho, 2010) and these may provide protection against the terrifying effects of degenerative diseases (Engel et al., 2016). In traditional medicine, it was found that plants that contained antioxidant compounds, could provide protection to the cells from the harmful and toxic properties of (ROS) (Uttara, Singh, Zamboni, \& Mahajan, 2009). Flavonoids and other phenolic plant origin compounds have also been reported as free radical scavengers (Manjamalai, Alexander, \& Grace, 2012). The use of compounds from natural sources for the pharmaceutical purpose has tremendously increased in Brazil as revealed by WHO (Santos, Oliveira, \& Tomassini, 1995) due to their antioxidants and antimicrobial properties. Despite of the fact that pharmaceutical industries have already formed a huge variety of new drugs and medicines in the recent years, but microorganisms has developed resistance to these drugs which is still increasing vigorously. If we generally analyze the situation, bacteria possess the genetic ability of acquiring resistance to drugs, which are used extensively as medicine (Cohen, 1992).

T. vulgaris is a small shrubby plant of $25 \mathrm{~cm}$ height. It has branched stems which are sturdy and their size ranges from 10 to $20 \mathrm{~cm}$. The shape of both the stem and branches is quadrangular moreover stems are narrow or wiry. It has fibrous ligneous roots. The leaves are narrow edged and 6-12 $\mathrm{mm}$ long, small in size and possess greenish-grey color. The whole plant is aromatic and attractive to bees, flies etc. due to its characteristic odor. Its flowers blooming from May to September having distinctive fragrances, may be white or blue- purple in color, small and grow in dense, whorled clusters. Thymol which is the major component of TEO, has much active role against the coccid bacteria. Thymol is generally used for various skin issues such as oily skin, sciatica, acne, dermatitis, and bug bites. It also relieves neuralgia and rheumatic pains (Escop \& Phytotherapy, 2003). It is worth mentioning that thyme has nonmedicinal usage, because of which food and aroma industries have a great interest in it recently. In food industries it is mostly used as culinary product and also for the preparation of food preservatives to maintain its quality chiefly due to its antioxidant effect. TEO constituents has a vital use as raw material in perfumery and cosmetic industries because it has a characteristic aroma and soothing effects on skin. T. vulgaris oil is a mixture of monoterpenes which have anti-oxidative, antimicrobial, medicinal drug, anti-tissue, antispasmodic, and antibacterial actions (MĂRCULESCU et al. 2007).

Flavonoids comprises of central three ring structure and it is mainly occurred as glycosides. They have phenolic groups which are involved in antioxidative activity and also in the reduction of carcinogenicity. flavonoids comprised of a range of biological activities such as antioxidant, anti-inflammatory, antimicrobial, anticancer and anti-allergic etc. (Ayoola et al. 2008; Madhu, Manukumar, Thribhuvan, \& Bhimangouda, 2014). Polyphenolics are the most potent phytochemicals because of their antioxidant property. These polyphenolic compounds may also act as chemical messengers, physiological regulators, and cell cycle inhibitors (Galeotti, Barile, Curir, Dolci, \& Lanzotti, 2008; ViudaMartos, Ruiz Navajas, Sánchez Zapata, Fernández-López, \& Pérez-Álvarez, 2010).Poly phenols protect the plants 
from stress, UV- radiations, and cuts. Free radicals cause different diseases which can be cured by the use of both components i.e. flavonoids and phenols. Tannin is also an important phytochemical which has the potential to cause toxicity. It has two types, one is condensed tannin which has flavonoid's large polymer, and second one is the hydrolysable polymer that comprises of monosaccharide core with numerous derivatives of catechin attached. These are generally bound with proteins and used as astringents in different cases including diarrhea, transudates, and skin bleedings (Bernhoft et al., 2010). The derivatives of tannins are also considered as primary antioxidants or free radical scavengers (CHAO, HSIU, \& HOU, 2002). Activity against cariogenic bacteria i.e. Porphyromonas gingivalis, Selenomonas artemidis, Streptococcus sobrinus, and Streptococcus mutans has been reported. Thymol has also showed extreme activity against some fungal strains and yeast including Aspergillus parasiticus, Aspergillus flavus, and Candida albicans, and it has also suppressed the synthesis of aflatoxins (Inouye, Uchida, \& Yamaguchi, 2001; Mahmoud, 1994).

Minimum inhibitory concentration (MIC) is the lowest concentration which is required for the inhibition of microbial growth after overnight incubation period (Habtamu \& Mekonnen, 2017). MIC acts as vital research tool which is used to determine the organism's susceptibility towards the antimicrobial agents and confront the pathogen's resistance. The lower will be the value of MIC, the less amount of drug will be required for inhibiting the microbial growth which means that the drug is more advantageous antimicrobial agent (Sharma, Singh, Paliwal, Chaudhary, \& Agarwal, 2013). The plant extracts contained voluminous phenolic compounds that have hydroxyl groups (-OH) which are attached with the aromatic rings (I. Gülçin, V. Mshvildadze, A. Gepdiremen, \& R. Elias, 2006). These phenolic compounds always block the chain oxidation reactions by the chelation of metals or by simply donating hydrogen atoms. That is the main reason due to which the metabolites found in these plant extracts often act as reducing agents, metal chelators, and antioxidants. It is evident from many studies that the total phenolic content (TPC) of plants have some antioxidant activity (Gülçin, Berashvili, \& Gepdiremen, 2005; GÜLÇİN, KİREÇCİ, AKKEMIK, Topal, \& HISAR, 2010). An antioxidant is any molecule which inhibits other molecules to get oxidize. While oxidation is a chemical phenomenon in which transfers electrons or hydrogen atoms from a simple substance to an oxidizing agent. Free radicals are produced as a result of oxidation reactions (E. M. Dauqan, Abdullah, \& Sani, 2011; Patil, 2013). These free radicals result in starting an oxidation chain reaction. If this chain reaction occurred successfully in a cell, it will produce severe harms or even death of that particular cell. These chain reactions can be stopped by removing free radical intermediates through antioxidative compounds, and in this way a number of oxidation reactions can be prevented (Patil, 2013; (Eqbal, Halimah, \& Aminah, 2012).

The purpose of this study is the determination of biological activities such as antibacterial activity of plant extracts against various gram positive and gram-negative bacterial strains and antioxidant activity of different concentrations of each fraction of plant extract by following non enzymatic assay.

\section{MATERIALS AND METHODS}

\section{Collection of Plant Material}

The plant material.vulgaris was used to prepared in the form of fine powder as reducing particle size increases contact with surface between plant material and extraction solvents.

\section{Extraction and Fractionation}

After the collection of finely powdered sample of plant, the organic extraction was done in which the powdered sample was weighed and soaked into various solvents. Seven conical flasks $(500 \mathrm{ml})$ were taken and in each 
flask 50g of powdered plant sample was poured by weighing with the help of electronic balance. The solvents were also measured to $500 \mathrm{ml}$ in a measuring cylinder and poured $500 \mathrm{ml}$ respective solvent in each flask that contained powdered plant material. First flask was contained with $50 \mathrm{~g}$ of plant sample soaked in $500 \mathrm{ml}$ of $\mathrm{n}$-hexane. Second flask was also consisted of $50 \mathrm{~g}$ plant sample along with $500 \mathrm{ml}$ of ethanol, while third flask was contained with $50 \mathrm{~g}$ of plant sample with $500 \mathrm{ml}$ methanol, the fourth flask was contained with $50 \mathrm{~g}$ of plant sample with $500 \mathrm{ml}$ acetone, fifth flask was contained with $50 \mathrm{~g}$ of plant sample with $500 \mathrm{ml}$ chloroform, sixth flask was contained with $50 \mathrm{~g}$ of plant sample with $500 \mathrm{ml}$ of ethyl acetate and seventh flask was contained with $50 \mathrm{~g}$ of plant sample with 500ml distilled water.

Then all of these flasks were placed into an incubating shaker at 37 degrees for 5 days. The mixture formed was filtered with Whatman filter paper, afterwards the filtrate of each extract was poured into separate glass beakers and then each filtrate was concentrated under reduced pressure at $40^{\circ} \mathrm{c}$ in rotary evaporator. As a result of which the extract obtained, was in a semi-solid form in case of all filtrates so these were then kept in a dried air oven, below 40 degrees for 1-2 days to evaporate the solvent completely. Henceforth all the solvents were evaporated completely and fractions were obtained i.e. n-hexane, ethanol, methanol, acetone, ethyl acetate, chloroform and water. Afterward these fractions were used for the evaluation of many biological activities of the said plant and many tests were done for determination of various bioactive compounds like saponin, tannins etc.(Azwanida, 2015). For performing various tests and assays on these fractions of each extract, the stock solution. was prepared by adding $1 \mathrm{mg}$ each extracted residue per ml of DMSO. It was further diluted with 10\% DMSO solution to made different concentrations of these fractions.

\section{Qualitative Analysis of Phytochemicals}

Following biochemical parameters were tested in the present study. The results were expressed as (-) for the absence and $(+)$ for the presence of bioactive compounds.

\section{Alkaloids determination}

Add a few $\mathrm{ml}$ of the filtrates of each extract to the test tubes and a drop of Mayer's reagent was added into it by the side of the test tube. A creamy or white precipitate indicated the test is positive (Evans, 1997).Picric acid was taken in water $1 \mathrm{~g} / 100 \mathrm{ml}$ to form a stock solution. Add few $\mathrm{ml}$ of this solution to the plant extracts in the test tubes. The appearance of creamy precipitates confirmed that the alkaloids were present in it (Mir, Parihar, Tabasum, \& Kumari, 2016).

For Flavonoids determination, stock solution was prepared first by mixing $1 \mathrm{ml}$ aluminum and remaining $99 \mathrm{ml}$ of distilled water. Few drops of $1 \%$ aluminum solution were added to a portion of each filtrate. A yellow coloration was observed in each extract that indicated the presence of flavonoids. The yellow coloration disappeared on standing (Harborne, 1973).

Terpenoids determination was performed using Five mg of each dry crude extract was mixed in $2 \mathrm{ml}$ of chloroform, and added $1 \mathrm{ml}$ of acetic anhydride and concentrated $\mathrm{H} 2 \mathrm{SO} 4(1 \mathrm{ml})$ was carefully added to the side of the test tube to form a layer. A reddish brown coloration of the inter face was formed to show positive results for the presence of terpenoids (Mir et al. 2016).

Tannins were determined using about 300 microliter of the plant extract was diluted with chloroform in a test tube and added in it 100 microliter of acetic anhydride and carefully added 100 microliters of sulphuric acid to the side of the test tube. A blue-black, or green precipitate formation was taken as evidence for the presence of tannins (Trease and Evans, 1989). 
Saponin contents were determined using bout $2 \mathrm{~g}$ of the powdered sample was boiled in $20 \mathrm{ml}$ of distilled water in a water bath and filtered. Saponine concentration was determined as describes by Mir et al., 2016)Steroids contents were determined using two $\mathrm{ml}$ of acetic anhydride was added to $0.5 \mathrm{~g}$ extract of each sample with $2 \mathrm{ml} \mathrm{H} 2 \mathrm{~S} 04$. The color changed from violet to blue or green in some samples indicated the presence of steroids (Mir et al. 2016).

\section{Antimicrobial Activity}

Antimicrobial assay of plant extracts was performed. Antimicrobial activity of extracts against different bacterial strains were determined by using disc diffusion method. Bacterial strains such as Salmonella Typhimurium, Acetobacter sp., Escherichia coli, and Staphylococcus dermatitis were used to determine bacterial activity.

\section{Disk diffusion method}

Prepared petri plates and bacterial culture flasks were placed in laminar flow. All the plates were labelled carefully and were swab one by one the bacterial cultures into respective plates by using sterilized bacterial culture swab. The sterilized disks were taken and 50 micro-liters of each extracts were put on the disks and then these disks were shifted on to the prepared culture plates. All the plates were then covered properly with paraffin paper and were incubated for 24 hours at 37 degrees. The extracts which have antibacterial activity showed clear zone of inhibition. Amoxicillin (antibiotic) was used as positive control and DMSO and water were used as negative controls. The whole process was repeated three times. The zones of inhibition were measured in millimeters (Gedikoğlu, Sökmen, \& Çivit, 2019).

\section{Antioxidant Assay}

DPPH solution was prepared by dissolving $1 \mathrm{mg}$ DPPH into 50ml of $10 \%$ DMSO and stirred for one hour. To obtain different concentrations of sample solution, $1 \mathrm{~mL}$ of DMSO solution was dissolved in $1 \mathrm{mg}$ of each fraction of extract which is in powdered form. This solution was diluted to prepare $1,0.5,0.25,0.1$, and $0.05 \mathrm{mg} / \mathrm{mL}$ concentrations with $10 \%$ DMSO. $1 \mathrm{ml}$ of DPPH solution was added to test tubes followed by the addition of equal volume of sample solution i.e. 1000 microliter. Mixture was shaken and kept in the dark at 25-28 degrees for 20 minutes. 10\% DMSO solution was taken as a blank. The antioxidant activity was estimated at $517 \mathrm{~nm}$ wavelength absorbance using UV-VIS double beam Spectrophotometer (Roby, Sarhan, Selim, \& Khalel, 2013).

The radical scavenging capacity was calculated by the following formula.

$\%$ Radical Scavenging Activity $=\frac{(\text { Absorbance of blank-Absorbance of sample })}{\text { Absorbance of blank }} \times 10$

\section{RESULTS}

Thymus vulgaris is the essential medicinal plant with significant activities. The study was conducted to determine the medicinal properties of plant by evaluating their bioactive compounds and biological activity (Fig. 1). Qualitative analysis was performed to determine phenolic compounds.

\section{Qualitative analysis}

Phytochemical screening of extracts was done and result are shown in table 1. Flavonoids, steroids and tannin were observed in methanol extract whereas $n$-hexane extract contained tannins and steroids. It was noted that steroids were present in all other extracts except water while the all-other compounds were absent in two or more extracts.

Table I: Phytochemical analysis of various extracts of T.vulgaris $L$. 
Pakistan Journal of Biochemistry and Biotechnology (PJBB) Volume 1, Issue 2 (2020), pp. 76-86

\begin{tabular}{|c|c|c|c|c|c|c|c|c|c|}
\hline \multirow[b]{2}{*}{$\begin{array}{l}\text { Sr. } \\
\text { No. }\end{array}$} & \multirow[b]{2}{*}{ Phytochemical tests } & \multicolumn{8}{|c|}{ Plant Extracts } \\
\hline & & Methanol & n-hexane & $\begin{array}{l}\text { Ethyl- } \\
\text { acetate }\end{array}$ & Ace & & Ethanol & Chloro-form & water \\
\hline \multirow[t]{2}{*}{1.} & $\begin{array}{l}\text { Alkaloids } \\
\text { Mayer's test }\end{array}$ & - & - & - & \multicolumn{2}{|c|}{-} & + & - & - \\
\hline & Picric acid test & - & - & - & \multicolumn{2}{|c|}{-} & - & - & - \\
\hline 2. & Saponin & - & - & + & \multicolumn{2}{|c|}{-} & + & - & - \\
\hline 3. & Tannins & + & + & - & \multicolumn{2}{|c|}{+} & + & + & - \\
\hline 4. & Flavonoids & + & - & + & \multicolumn{2}{|c|}{-} & - & - & + \\
\hline 5. & $\begin{array}{c}\text { Terpenoids } \\
\text { Salkowski test }\end{array}$ & - & - & + & \multicolumn{2}{|c|}{-} & - & - & + \\
\hline 6. & Steroids & + & + & + & \multicolumn{2}{|c|}{+} & - & + & - \\
\hline \multirow{2}{*}{$\begin{array}{l}\text { Sr. } \\
\text { No. }\end{array}$} & \multirow[b]{2}{*}{ Extracts } & \multicolumn{8}{|c|}{$\begin{array}{l}\text { Zone of inhibition } \\
\text { (mm) }\end{array}$} \\
\hline & & \multicolumn{2}{|c|}{$\begin{array}{l}\text { Staphlococcus } \\
\text { dermititis }\end{array}$} & \multicolumn{3}{|c|}{$\begin{array}{c}\text { Salmonella } \\
\text { typhimuriuim }\end{array}$} & Eschrichia coli & \multicolumn{2}{|c|}{ Acetobacter sp. } \\
\hline 1. & Methanol & \multicolumn{2}{|c|}{$3.33 \pm 0.47$} & \multicolumn{2}{|c|}{$9.33 \pm 0.94$} & & $4.3 \pm 1.2$ & \multicolumn{2}{|c|}{$12 \pm 1.33$} \\
\hline 2. & Ethanol & \multicolumn{2}{|c|}{$9.30 \pm 0.92$} & \multicolumn{2}{|c|}{$8.32 \pm 0.78$} & & $4.1 \pm 1.01$ & \multicolumn{2}{|c|}{$12 \pm 1.34$} \\
\hline 3. & n-hexane & \multicolumn{2}{|c|}{$11.6 \pm 0.33$} & \multicolumn{2}{|c|}{$11 \pm 0.81$} & \multicolumn{2}{|r|}{$0.33 \pm 0.04$} & \multicolumn{2}{|c|}{$12 \pm 1.35$} \\
\hline 4. & Acetone & \multicolumn{2}{|c|}{$12 \pm 0.8$} & \multicolumn{2}{|c|}{$10 \pm 0.78$} & \multicolumn{2}{|r|}{$5.32 \pm 2.21$} & \multicolumn{2}{|c|}{$12 \pm 1.36$} \\
\hline 5. & Chloroform & \multicolumn{2}{|c|}{$11.6 \pm 0.48$} & \multicolumn{2}{|c|}{$10.3 \pm 0.47$} & & $1.33 \pm 0.37$ & & \pm 1.37 \\
\hline 6. & Ethyl acetate & $12=$ & & $1.33=$ & & & $11 \pm 0.81$ & & \pm 1.38 \\
\hline 7. & Water & 10 & & $7.3=$ & & & $1.6 \pm 0.47$ & & \pm 1.39 \\
\hline 8. & Amoxicillin & 1.33 & 36 & $45 \pm$ & & & $42 \pm 1.2$ & & \pm 0.87 \\
\hline
\end{tabular}

$+=$ present, $-=$ not present 


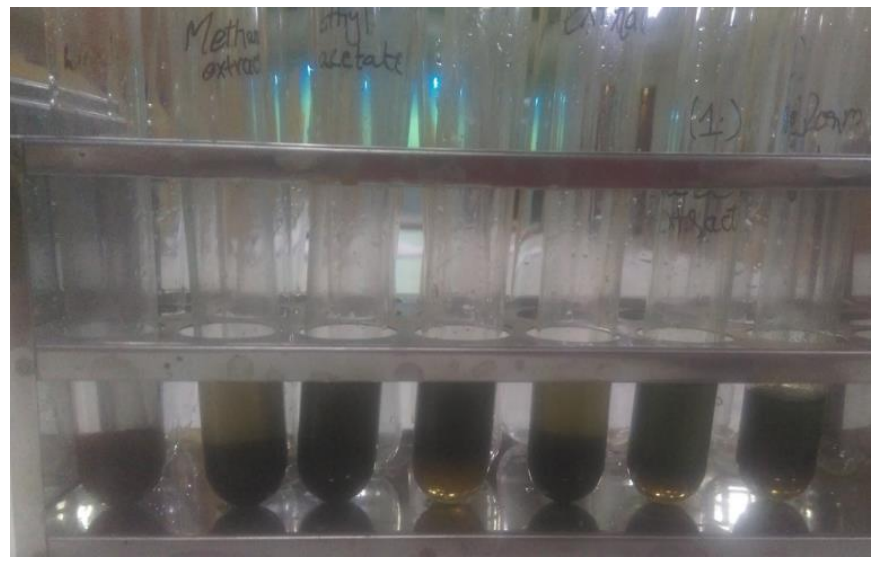

Fig. 1: Qualitative tests for phytochemicals in plant extracts.

\section{Antibacterial activity}

Disc diffusion method was performed for antibacterial activity shown in Fig. 2. The result showed that plant have potent antibacterial activity. Result showed potent antibacterial activity against the strain of Staphylococcus dermatitis in which methanolic extract showed lower activity $(3.33 \pm 0.47)$ while ethyl acetate extract showed higher activity $(12 \pm 0.81)$. In the strain of Salmonella typhimurium n-hexane showed higher activity $(11 \pm 0.81)$ whereas ethyl acetate showed lowest activity $(1.33 \pm 1.24)$. Against $E$. coli strain n-hexane extract showed lower activity $(0.33 \pm 0.04)$ and ethyl acetate showed highest activity (11 \pm 0.81$)$. In case of Acetobacter $s p$. n-hexane showed highest activity (18 \pm 0.81$)$ while ethanolic extract showed lower activity (1.3 \pm 0.47$)$. Antibacterial activity in terms of inhibition zone in millimeters was observed and statistically analyzed which showed significant results.

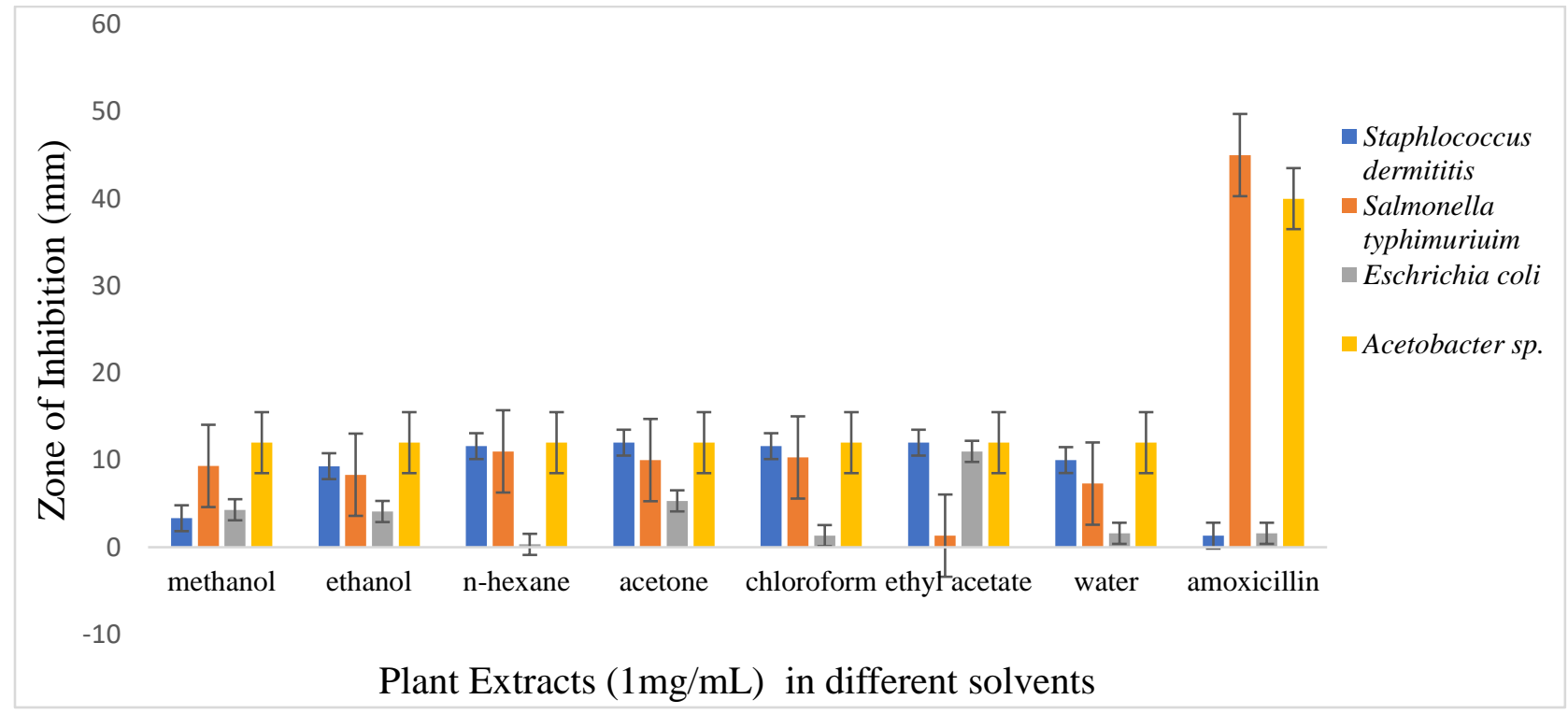


Figure 2: Antibacterial activity of different extracts
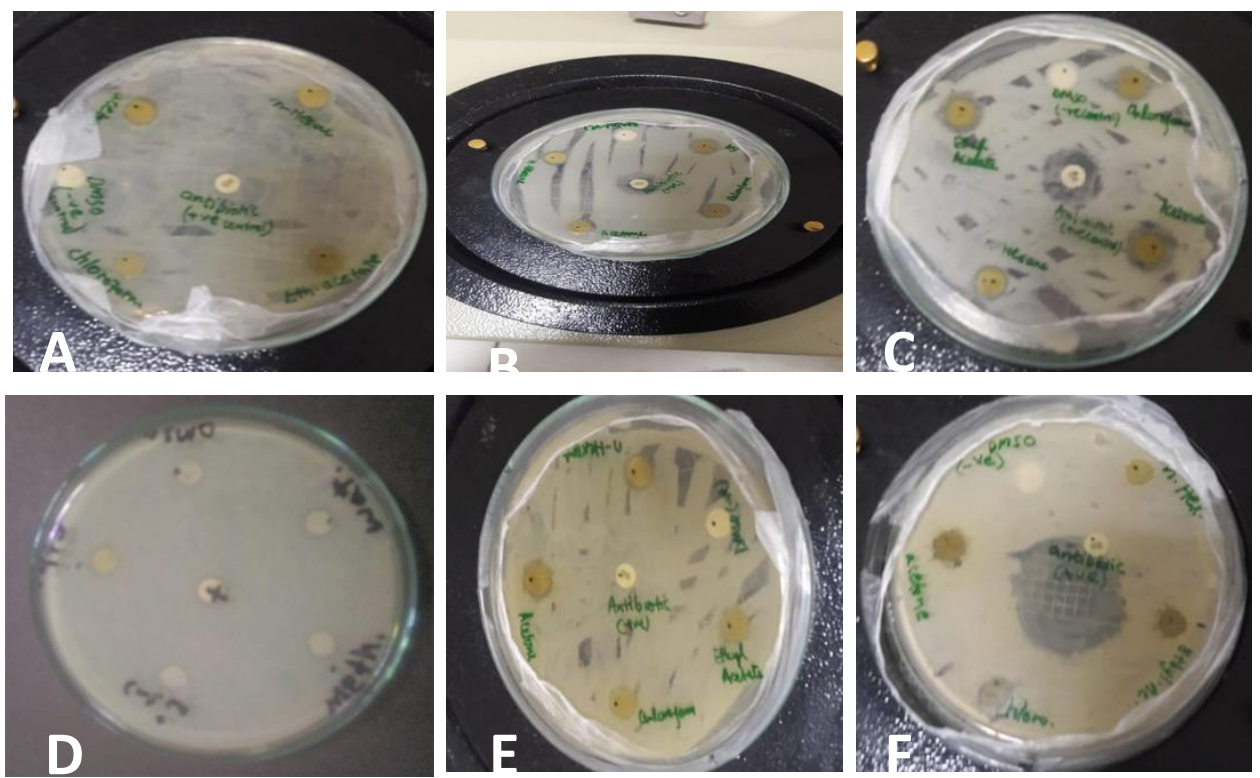

Fig. 3: Antibacterial activity (mm) of T. vulgaris (chloroform, ethyl acetate, n-hexane, DMSO, acetone, amoxicillin) indicated by zone of inhibition. A- E. coli , B-Staphylococcus dermititis, C-Salmonella Typhimurium, D-Acetobacter sp, E-Acetobacter sp., F-Staphylococcus dermititis.

\section{DPPH free radical scavenging activity}

Antioxidant potential was evaluated. The DPPH scavenging activity was found to be higher in water extract at the concentration of $0.25 \mathrm{mg} / \mathrm{ml}(8.468 \pm 2.553)$ and $0.1 \mathrm{mg} / \mathrm{ml}(5.392 \pm 2.460)$ while methanolic extract at the concentration of $0.1 \mathrm{mg} / \mathrm{ml}$ showed minimum activity $(3.836 \pm 0.0005)$. The data was statistically analyzed and showed significant results represented in table 3 .

Table 2: DPPH free radical scavenging potential of different sub fractions of $T$. vulgaris

\begin{tabular}{|c|c|c|c|}
\hline $\begin{array}{c}\text { Sr. } \\
\text { No. }\end{array}$ & Extracts & $\begin{array}{c}\text { Concentration } \\
(\mathbf{m g} / \mathbf{m l})\end{array}$ & $\begin{array}{c}\text { DPPH percent inhibition (\%) } \\
(\mathbf{m e a n} \pm \text { S.D) }\end{array}$ \\
\hline 1. & Methanol & 1 & $1.518 \pm 0.001$ \\
\hline
\end{tabular}


Pakistan Journal of Biochemistry and Biotechnology (PJBB) Volume 1, Issue 2 (2020), pp. 76-86

\begin{tabular}{|c|c|c|c|}
\hline & & 0.5 & $1.302 \pm 0.003$ \\
\hline & & 0.25 & $0.615 \pm 0.003$ \\
\hline & & 0.1 & $3.836 \pm 0.0005$ \\
\hline & & 0.05 & $4.264 \pm 0.001$ \\
\hline \multirow[t]{5}{*}{2.} & \multirow[t]{5}{*}{ Ethanol } & 1 & $1.085 \pm 0.001$ \\
\hline & & 0.5 & $1.266 \pm 0.003$ \\
\hline & & 0.25 & $3.763 \pm 0.001$ \\
\hline & & 0.1 & $0.759 \pm 0.002$ \\
\hline & & 0.05 & $0.578 \pm 0.0005$ \\
\hline \multirow[t]{5}{*}{3.} & \multirow[t]{5}{*}{ n- hexane } & 1 & $20.153 \pm 0.16$ \\
\hline & & 0.5 & $9.518 \pm 0.16$ \\
\hline & & 0.25 & $0.289 \pm 0.29$ \\
\hline & & 0.1 & $0.976 \pm 0.18$ \\
\hline & & 0.05 & $1.194 \pm 0.0$ \\
\hline \multirow[t]{5}{*}{4.} & \multirow[t]{5}{*}{ Ethyl acetate } & 1 & $2.278 \pm 0.002$ \\
\hline & & 0.5 & $0.904 \pm 0.001$ \\
\hline & & 0.25 & $0.433 \pm 0.0005$ \\
\hline & & 0.1 & $2.495 \pm 0.003$ \\
\hline & & 0.05 & $1.121 \pm 0.0007$ \\
\hline \multirow[t]{5}{*}{5.} & \multirow[t]{5}{*}{ Chloroform } & 1 & $0.868 \pm 0.001$ \\
\hline & & 0.5 & $4.198 \pm 0.001$ \\
\hline & & 0.25 & $3.184 \pm 0.027$ \\
\hline & & 0.1 & $0.904 \pm 0.002$ \\
\hline & & 0.05 & $2.894 \pm 0.004$ \\
\hline \multirow[t]{5}{*}{6.} & \multirow[t]{5}{*}{ Acetone } & 1 & $1.483 \pm 0.001$ \\
\hline & & 0.5 & $3.474 \pm 0.007$ \\
\hline & & 0.25 & $0.578 \pm 0.001$ \\
\hline & & 0.1 & $4.775 \pm 0.003$ \\
\hline & & 0.05 & $4.270 \pm 0.003$ \\
\hline \multirow[t]{5}{*}{7.} & \multirow[t]{5}{*}{ Water } & 1 & $4.415 \pm 0.125$ \\
\hline & & 0.5 & $0.506 \pm 0.062$ \\
\hline & & 0.25 & $8.468 \pm 2.553$ \\
\hline & & 0.1 & $5.392 \pm 2.460$ \\
\hline & & 0.05 & $6.659 \pm 0.062$ \\
\hline
\end{tabular}




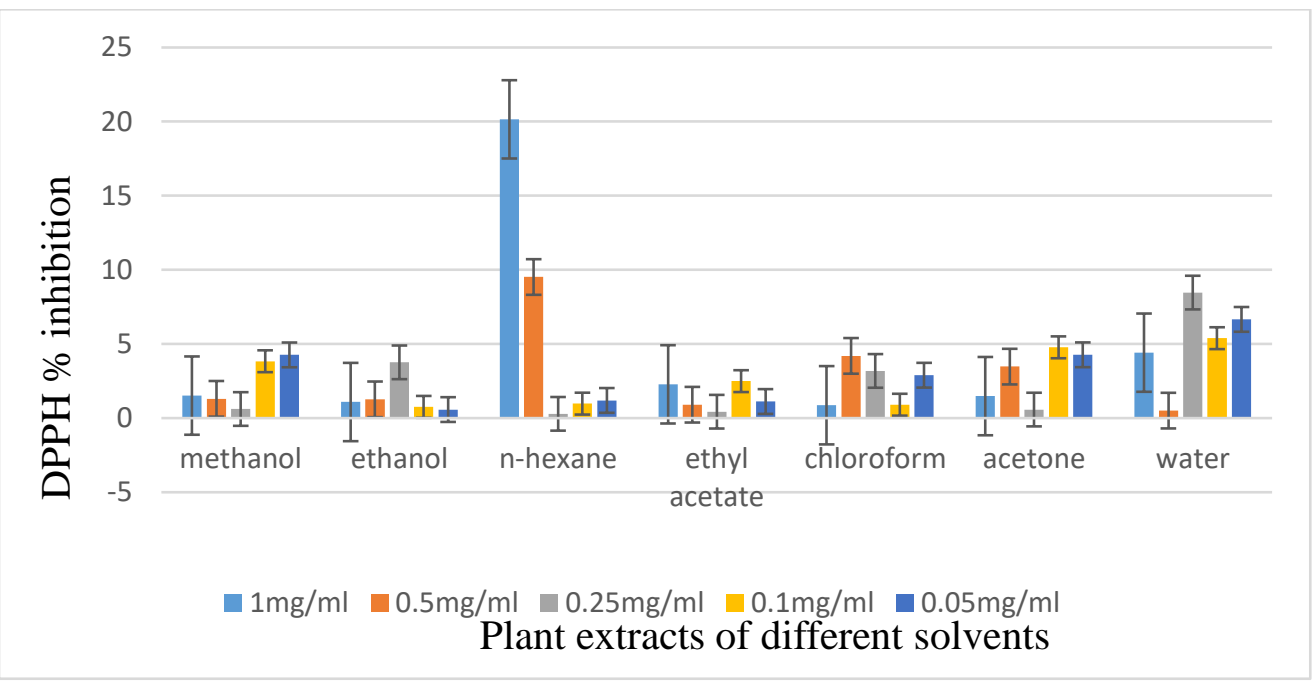

Fig. 4: Graphical representation of DPPH radical scavenging activity in seven extracts of $T$. vulgaris L.

\section{DISCUSSION}

Medicinal plants have been used traditionally for curing many diseases and having great history in pharmacology. Now a days medicinal herbs are considered the most effective and safe medication throughout the world because plant contain natural antioxidants, antimicrobial, and phytochemical compounds. T. vulgaris has many bioactive compounds and is already reported to possess several biological activities including cytotoxicity, antimicrobial activity, and antioxidant activity so the current study has screened various activities of plant extracts.

Phytochemical screening of plant extracts was carried out and shown in the Table 1. According to the observation the plant extracts contained various secondary metabolites like alkaloids, saponin, tannin, terpenoids, flavonoids etc. Alkaloids was present in only a single extract while all other compounds were absent in one or two extracts. Moreover, alkaloids have been reported as powerful poisonous compounds and played a potent role in numerous activities (Iqbal et al., 2015). Several flavonoids have been reported for their hepatoprotective activities (Tapas, Sakarkar, \& Kakde, 2008). Saponin showed antineoplastic effects and the effect of hemolysis of red blood cells. Steroids and tannins showed antisecticidal, antiviral and antibiotic properties. It was proved that plant was progressively valuable because it has many bioactive compounds which were potent to manufacturing drugs and to cure various ailments. As per earlier studies have reported that $T$. vulgaris have phytochemical compounds i.e. flavonoids, tannins, saponin, phlobatannins, alkaloids, sterols, glycosides and quinones etc. in water, ethanol, and nbutanol extracts (Briskin, 2000).

Phytochemicals studies have showed effective antimicrobial components in T. vulgaris (thyme) extract (Aminzare, Hashemi, Abbasi, Mohseni, \& Amiri, 2018). The antibacterial activity of T. vulgaris plant extracts was tested against gram-positive and gram-negative bacteria. Plant extracts displayed significant antibacterial effects against the tested bacteria (Table 2). The maximum effect was found against Staphylococcus dermatitis $((12 \pm 0.81)$.), and the minimum activity was shown against Acetobacter $s p$. (1.3 \pm 0.47$)$. The antibacterial activity was also reported against Salmonella typhimurium and Escherichia coli. Antioxidant potential was also evaluated by the DPPH radical 
scavenging assay. The plant has showed good antioxidant activity which was described in Table 3 . Many concentrations of each fraction were made to determine the antioxidant potential and their absorbance was measured triplicate readings were taken which showed that water and chloroform have high antioxidant activity $((8.468 \pm 2.553)$, $(4.198 \pm 0.001)$ respectively, and methanol extract have lower activity $(3.836 \pm 0.0005$

\section{Conclusion}

The present study was used to investigate the bioactivity of $T$. vulgaris. Plant extracts were used for the evaluation of qualitative tests. In the qualitative analysis phytochemical constituents were observed which have great application in pharmaceuticals and therapeutics. The biological activities were also carried out i.e. antioxidant activity such as free radical scavenging activity which showed potent efficacy in water and chloroform extracts. Extracts of $T$. vulgaris have good antibacterial activity against different bacterial strains which revealed that phytomedicines are a good approach to cure many infectious diseases as these contain natural compounds hence lowering the side effects to minimum. So it was concluded that this plant contained a number of phenolic compounds which provide a great help in the selection of non-toxic and effective compounds for the synthesis of new drugs.

\section{Acknowledgments}

This study was supported by University of Central Punjab, Lahore, Pakistan, Faculty of Life Sciences, Department of Biochemistry.

\section{Conflict of Interest}

There is no conflict of interest in this research study.

\section{References}

Akanda, M. R., Kim, I.-S., Ahn, D., Tae, H.-J., Tian, W., Nam, H.-H., . . Park, B.-Y. (2017). In vivo and in vitro hepatoprotective effects of Geranium koreanum methanolic extract via downregulation of MAPK/Caspase-3 pathway. Evidence-Based Complementary and Alternative Medicine, 2017.

Aminzare, M., Hashemi, M., Abbasi, Z., Mohseni, M., \& Amiri, E. (2018). Vibriosis phytotherapy: A review on the most important world medic-inal plants effective on Vibrio spp. Journal of Applied Pharmaceutical Science, 8(01), 170-177.

Arunkumar, S., \& Muthuselvam, M. (2009). Analysis of phytochemical constituents and antimicrobial activities of Aloe vera L. against clinical pathogens. World Journal of Agricultural Sciences, 5(5), 572-576.

Ayoola, G., Coker, H., Adesegun, S., Adepoju-Bello, A., Obaweya, K., Ezennia, E., \& Atangbayila, T. (2008). Phytochemical screening and antioxidant activities of some selected medicinal plants used for malaria therapy in Southwestern Nigeria. Tropical Journal of Pharmaceutical Research, 7(3), 1019-1024.

Babovic, N., Djilas, S., Jadranin, M., Vajs, V., Ivanovic, J., Petrovic, S., \& Zizovic, I. (2010). Supercritical carbon dioxide extraction of antioxidant fractions from selected Lamiaceae herbs and their antioxidant capacity. Innovative Food Science \& Emerging Technologies, 11(1), 98-107.

Baydar, H., Sağdiç, O., Özkan, G., \& Karadoğan, T. (2004). Antibacterial activity and composition of essential oils from Origanum, Thymbra and Satureja species with commercial importance in Turkey. Food control, 15(3), 169-172.

Briskin, D. P. (2000). Medicinal plants and phytomedicines. Linking plant biochemistry and physiology to human health. Plant physiology, 124(2), 507-514.

Chan, C. L., Gan, R. Y., \& Corke, H. (2016). The phenolic composition and antioxidant capacity of soluble and bound extracts in selected dietary spices and medicinal herbs. International journal of food science \& technology, 51(3), 565-573. 
CHAO, P.-D. L., HSIU, S.-L., \& HOU, Y.-C. (2002). Flavonoids in herbs: biological fates and potential interactions with xenobiotics. Journal of Food and Drug Analysis, 10(4).

Cohen, M. L. (1992). Epidemiology of drug resistance: implications for a post—antimicrobial era. Science, 257(5073), 1050-1055.

Dauqan, E., \& Abdullah, A. (2017). Medicinal and functional values of thyme (Thymus vulgaris L.) herb. Journal of Applied Biology \& Biotechnology, 5(02), 017-022.

Dauqan, E. M., Abdullah, A., \& Sani, H. A. (2011). Natural antioxidants, lipid profile, lipid peroxidation, antioxidant enzymes of different vegetable oils. Advance Journal of Food Science and Technology, 3(4), 308-316.

Engel, R., Szabo, K., Abranko, L., Rendes, K., Füzy, A., \& Takács, T. n. (2016). Effect of arbuscular mycorrhizal fungi on the growth and polyphenol profile of marjoram, lemon balm, and marigold. Journal of agricultural and food chemistry, 64(19), 3733-3742.

Eqbal, D., Halimah, A., \& Aminah, A. (2012). Antioxidants enzyme: Effect of different concentrations of red palm olein and different vegetable oils on antioxidant enzymes on normal and stressed. In: InTech.

Escop, \& Phytotherapy, E. S. C. o. (2003). ESCOP Monographs: the scientific foundation for herbal medicinal products: Thieme.

Galeotti, F., Barile, E., Curir, P., Dolci, M., \& Lanzotti, V. (2008). Flavonoids from carnation (Dianthus caryophyllus) and their antifungal activity. Phytochemistry Letters, 1(1), 44-48.

Gedikoğlu, A., Sökmen, M., \& Çivit, A. (2019). Evaluation of Thymus vulgaris and Thymbra spicata essential oils and plant extracts for chemical composition, antioxidant, and antimicrobial properties. Food science \& nutrition, 7(5), 1704-1714.

Gülçin, İ., Berashvili, D., \& Gepdiremen, A. (2005). Antiradical and antioxidant activity of total anthocyanins from Perilla pankinensis decne. Journal of ethnopharmacology, 101(1-3), 287-293.

GÜLÇIN, İ., KİREÇCI, E., AKKEMIK, E., Topal, F., \& HISAR, O. (2010). Antioxidant and antimicrobial activities of an aquatic plant: Duckweed (Lemna minor L.). Turkish Journal of Biology, 34(2), 175-188.

Gülçin, I., Mshvildadze, V., Gepdiremen, A., \& Elias, R. (2006). Screening of antiradical and antioxidant activity of monodesmosides and crude extract from Leontice smirnowii tuber. Phytomedicine, 13(5), 343-351.

Habtamu, A., \& Mekonnen, Y. (2017). Evaluation of the antibacterial activities of leaf extracts of Achyranthus aspera. African Journal of Bacteriology Research, 9(2), 9-14.

Harborne, J. (1973). Phytochemical methods chapman and Hall. Ltd. London, 4, 49-188.

Inouye, S., Uchida, K., \& Yamaguchi, H. (2001). In-vitro and in-vivo anti-Trichophyton activity of essential oils by vapour contact. Mycoses, 44(3-4), 99-107.

Janssen, A., Scheffer, J., \& Svendsen, A. B. (1987). Antimicrobial activity of essential oils: a 1976-1986 literature review. Aspects of the test methods. Planta medica, 53(05), 395-398.

Madhu, C., Manukumar, H., Thribhuvan, K., \& Bhimangouda, R. P. (2014). Phytochemical, nutritional and mineral constituents of illicium verum hook (star anise). World Journal of Pharmaceutical Sciences, 3(2), 2888-2896.

Mahmoud, A. L. (1994). Antifungal action and antiaflatoxigenic properties of some essential oil constituents. Letters in Applied Microbiology, 19(2), 110-113.

Manjamalai, A., Alexander, T., \& Grace, V. B. (2012). Bioactive evaluation of the essential oil of Plectranthus amboinicus by GC-MS analysis and its role as a drug for microbial infections and inflammation. Int J Pharm Pharm Sci, 4(3), 205-211.

Mir, M. A., Parihar, K., Tabasum, U., \& Kumari, E. (2016). Estimation of alkaloid, saponin and flavonoid, content in various extracts of Crocus sativa. J Med Plants Stud, 4(5), 171-174.

Mousavi, S. M., Wilson, G., Raftos, D., Mirzargar, S. S., \& Omidbaigi, R. (2011). Antibacterial activities of a new combination of essential oils against marine bacteria. Aquaculture international, 19(1), 205-214.

Pan, M.-H., Lai, C.-S., \& Ho, C.-T. (2010). Anti-inflammatory activity of natural dietary flavonoids. Food \& function, l(1), 15-31. 
Patil, D. (2013). Role of antioxidants in stability of edible oil. Trends Post-Harvest Technol, 1, 68-73.

Prakash, P., \& Gupta, N. (2005). Therapeutic uses of Ocimum sanctum Linn (Tulsi) with a note on eugenol and its pharmacological actions: a short review. Indian journal of physiology and pharmacology, 49(2), 125.

Roby, M. H. H., Sarhan, M. A., Selim, K. A.-H., \& Khalel, K. I. (2013). Evaluation of antioxidant activity, total phenols and phenolic compounds in thyme (Thymus vulgaris L.), sage (Salvia officinalis L.), and marjoram (Origanum majorana L.) extracts. Industrial Crops and Products, 43, 827-831.

Rota, M. C., Herrera, A., Martínez, R. M., Sotomayor, J. A., \& Jordán, M. J. (2008). Antimicrobial activity and chemical composition of Thymus vulgaris, Thymus zygis and Thymus hyemalis essential oils. Food control, 19(7), 681-687.

Santos, P. R. V. d., Oliveira, A. C. X. d., \& Tomassini, T. C. B. (1995). Controle microbiológico de produtos fitoterápicos. Rev Farm Bioquím Univ São Paulo, 31(1), 35-38.

Sharma, V., Singh, R., Paliwal, R., Chaudhary, U., \& Agarwal, A. (2013). MIC values of inflorescence and leaves extracts of Achyranthes aspera against usual pathogenic bacterial strains. Asian Journal of Pharmaceutical and Clinical Research, 6(1), 185-187.

Šulniūtè, V., Pukalskas, A., \& Venskutonis, P. R. (2017). Phytochemical composition of fractions isolated from ten Salvia species by supercritical carbon dioxide and pressurized liquid extraction methods. Food chemistry, 224, $37-47$.

Tapas, A. R., Sakarkar, D., \& Kakde, R. (2008). Flavonoids as nutraceuticals: a review. Tropical Journal of Pharmaceutical Research, 7(3), 1089-1099.

Van den Broucke, C., Lemli, J., \& Lamy, J. (1983). Action spasmolytique des flavones de differentes especes de Thymus. Plantes Med Phytother, 16(4), 310-317.

Viuda-Martos, M., Ruiz Navajas, Y., Sánchez Zapata, E., Fernández-López, J., \& Pérez-Álvarez, J. A. (2010). Antioxidant activity of essential oils of five spice plants widely used in a Mediterranean diet. Flavour and Fragrance Journal, 25(1), 13-19. 